\title{
Familial Hypertrichosis Cubiti: Hairy Elbows Syndrome
}

\author{
PETER BEIGHTON
}

\author{
From Division of Medical Genetics, fohns Hopkins Hospital, Baltimore, U.S.A.
}

Genetically determined hypertrichosis is uncommon, but several forms of familial hairiness have been described. In some kindreds the unusual hairiness has been generalized, while in others, the hypertrichosis has been confined to a specific site on the body.

The purpose of this paper is to report the occurrence of undue hairiness of the elbow regions in members of an Amish family, and to discuss the genetic significance of the condition. No previous descriptions of hypertrichosis of this distribution could be found in the literature, and it is therefore suggested that the condition be termed familial hypertrichosis cubiti or the hairy elbows syndrome.

\section{Case Report}

A white girl was born in 1956 after an uneventful pregnancy and delivery. Unusual hairiness of the elbow regions was observed soon after her birth. This hair increased in length and thickened in texture during infancy, reaching a maximum at the age of 5 , before beginning to regress. Apart from her elbow regions, she was not unduly hairy in early life, though a good head of hair was apparent in a photograph which had been taken at the age of 6 weeks. Like many members of her family, the patient was of small stature, but her general health was otherwise normal.

Examination in 1969 revealed a pleasant intelligent girl with hypertrichosis involving the lower third of the upper arm and the upper third of the forearm. This hair was long, dark, and coarse, but the underlying skin was normal (Fig. 1). The hair of her head and eyebrows and her pubic and axillary hair were normal for her age, and no other localized hypertrichosis was present. Her finger-nails were short, but not dysplastic, and her teeth were unremarkable (Fig. 2). She was only $125 \mathrm{~cm}$. tall, but her bodily proportions were normal. No other abnormality was detected on physical examination.

Received 20 November 1969.

Present address: St. Thomas' Hospital, London S.E.1.
Her younger brother, born in 1957, was also noted to have hairy elbows soon after birth. He was also small in stature, and, like his sister, his hypertrichosis became worse in infancy and then regressed in later childhood. Hair was present over the spine during his early years, but it had disappeared by the time that he was examined in 1969.

Two younger brothers had phenylketonuria, and a younger sister was apparently normal. None of these sibs had any hypertrichosis (Fig. 3).

Her father was also hairy, with thick eyebrows, a forceful beard, and hairy arms. However, these findings could not be considered to be outside the accepted range of normality. He stated that he had been more hairy during childhood, and that his hypertrichosis usually increased during the winter. His finger-nails and teeth were normal, and he was otherwise well.

The paternal grandfather, and several of her father's sibs, were also said to be somewhat hairy, but precise details were not available.

Her kindred were members of the Pennsylvania community of Old Order Amish, a highly inbred religious isolate. Both of her parents were of small stature, probably because they were heterozygotes for the WeillMarchesani syndrome, and the patient's own dwarfism could possibly be attributed to the same abnormal gene.

\section{Discussion}

Excessive generalized hairiness may be a manifestation of hyperactivity of the adrenal cortex, or of an underlying metabolic disorder, such as porphyria or a mucopolysaccharidosis. Widespread hairiness is also the major feature of hypertrichosis universalis congenita, which is inherited as an autosomal dominant trait (Gates, 1946).

Localized hypertrichosis may occur in association with a naevus, or over a spina bifida. For instance, Miss Belle Carter, the 'Lady with a Mane' had an area of hypertrichosis associated with a naevus pilosus over the upper dorsal spine (Danforth, 1925). Circumscribed hypertrichosis may be sporadic, and rare familial varieties have also been 


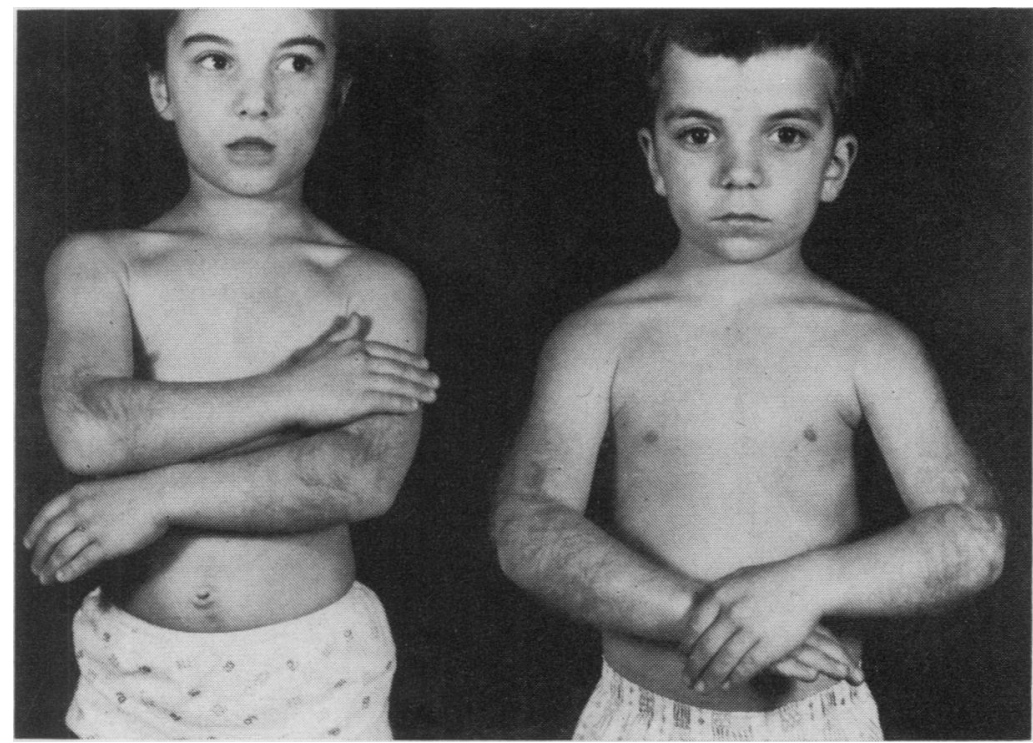

FIG. 1. The patient and her brother at the respective ages of 7 and 6 years. Their elbow regions are remarkably hairy.

described (Butterworth and Strean, 1962). The Burgomaster of Graunau, who was killed in 1572 when his luxuriant beard caught in his horse's stirrup (Beigel, 1868), probably had a sporadic form of hypertrichosis, while one variety of familial localized hypertrichosis was exemplified by The Seven Sutherland Sisters, who were depicted by Durant and Durant (1957). These long-haired ladies, in addition to performing as Vaudeville artistes, made a fortune from advertising hair tonic!

It is of interest that the hypertrichosis of the affected sibs increased during infancy, and then resolved in later childhood, as this sequence of events has previously been noted in hypertrichosis universalis congenita (Cockayne, 1933). It is also noteworthy that their nails were short, but not

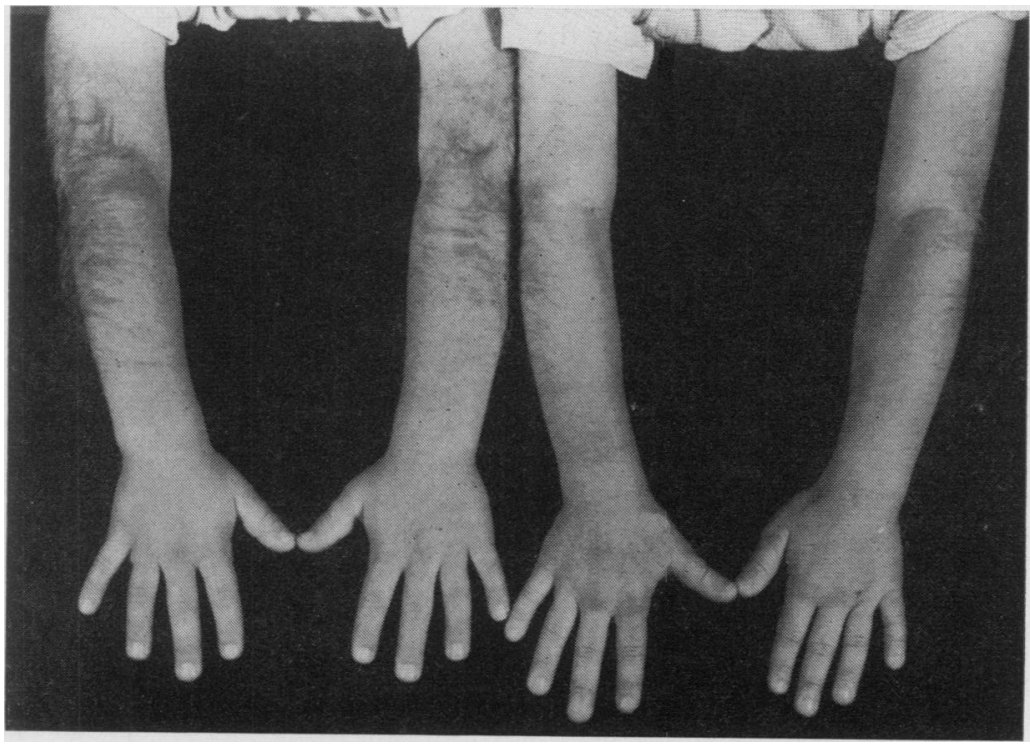

FIG. 2. The finger-nails of the affected sibs are short, but not dysplastic. 
dysplastic, as abnormalities of the nails sometimes occur in association with this type of hypertrichosis (Pillsbury, Shelley, and Kligman, 1957). Abnormalities of the teeth and gums have also been encountered in affected subjects, but these changes are not invariable concomitants.

The patients' short stature was probably not related in any way to their hypertrichosis, as various forms of familial dwarfism are not uncommon in the Amish community.

There was no evidence of systemic ramifications, and the patient's localized hypertrichosis seems to be nothing more than an interesting curiosity. However, the occurrence of the condition in 2 out of 5 sibs suggests a genetic aetiology. As the kindred was highly inbred, it is tempting to postulate an autosomal recessive mode of inheritance. On the other hand, the presence of hairiness in the father and several of his relations might indicate that the disorder is due to a dominant gene, which is very variable in its clinical expression. This dilemma may be resolved when the affected children raise their own families.

\section{Summary}

Two Amish sibs were born with unusual hairiness of their elbow regions. This form of localized hypertrichosis, familial hypertrichosis cubiti, has not been previously described. Their finger-nails were short, but not dysplastic, and no other systemic ramifications were present.

I am grateful to Professor V. A. McKusick for his permission to examine the patients, and for his guidance during the preparation of the case report.

The author was supported by a grant from the National Foundation for Birth Defects (CRCS-48).

\section{REFBRENCES}

Beigel, H. (1868). Ueber abnorme Haarentwickelung beim Menschen. Virchows Archiv für pathologische Anatomie und Physiologie und für klinische Medizin, 44, 418-427. (Cited by Gates, 1946.)

Butterworth, T., and Strean, L. P. (1962). Clinical Genodermato$\log y$, p. 89. Williams and Wilkins, Baltimore.

Cockayne, E. A. (1933). Inherited Abnormalities of the Skin and its Appendages, pp. 245-248. Oxford University Press, London.

Danforth, C. H. (1925). Studies on hair with special reference to hypertrichosis. Archives of Dermatology and Syphilogy, 12, 380401.

Durant, J., and Durant, A. (1957). Pictorial History of the American Circus, pp. 98-105. A. S. Barnes, New York.

Gates, R. R. (1946). Human Genetics, Vol. 1, pp. 337-339. MacMillan, New York.

Pillsbury, D. M., Shelley, W. B., and Kligman, A. M. (1957). Dermatology, p. 1004 . W. B. Saunders, Philadelphia. 